\title{
NUEVAS GLOSAS ROMANCES EN UN MANUSCRITO SILENSE
}

\author{
CÉsar Hernández Alonso \\ Universidad de Valladolid
}

En la tesis doctoral de Miguel C. Vivancos Gómez ${ }^{1}$, dirigida por el Dr. José Antonio Fernández Flórez, sobre "Glosas y notas marginales de los manuscritos visigóticos del Monasterio de Santo Domingo de Silos» se recogían casi cinco mil quinientas glosas, muchas de ellas desconocidas hasta ese momento.

Pendientes de que se realice la compilación y el estudio de todos los códices visigóticos españoles, este trabajo supone un avance importante para los estudios paleográficos y una notable aportación a los filológicos. Especialmente en lo que a nosotros nos atañe, porque Miguel Vivancos tuvo la fortuna de reconocer, entre otras, dieciocho nuevas glosas romances en el Liber Comicus (BNP, N.a.l. 2171) en un pasaje de la Pasión correspondiente a la Feria $V$ in cena Domini. Son glosas algo más tardías que las del códice BL, Add. 30853, en que aparecen las conocidas hasta ahora como «Glosas Silenses», cuyo número (368) y relevancia para los estudios del nacimiento de nuestra lengua son verdaderamente fundamentales, según mostramos en su día ${ }^{2}$. En las dieciocho nuevas, que analizamos aquí -no podían quedar en barbecho- se mezclan rasgos carolinos con otros visigóticos, todas ellas aparecen interlineadas - hecho inusual en las del Monasterio de Silos- y sin signos de remisión. Entre ellas no hay interferencias de comentarios gramaticales, ni de notaciones musicales, y casi to-

\footnotetext{
${ }^{1}$ Fue defendida en la Universidad de Valladolid, el 27 de septiembre de 1994, y de cuyo tribunal formé parte. En aquel momento el P. Miguel Vivancos era el bibliotecario de la del Monasterio de Silos. Este trabajo se ha publicado, con el mismo título, en la colección Studia Silensia (Abadía de Silos, 1996), por el que citamos.

${ }^{2}$ C. Hernández Alonso, J. Fradejas Lebrero, G. Martínez Díez y J. M. Ruiz Asencio, Las Glosas Emilianenses y Silenses, edición crítica y facsímil, Ayuntamiento de Burgos, 1993. Contiene análisis de todas las glosas de los manuscritos estudiados, transcripción revisada y estudios histórico, literario, paleográfico y lingüístico.
} 
das son monorrémicas, es decir, formadas por sinónimos o cuasisinónimos romances ${ }^{3}$.

El manuscrito en que aparecen consta, actualmente, de unos fragmentos del Evangelium Nicodemi (de los Apócrifos) y unas Interrogationes de fide catholica. Les siguen una ratio numerum, un Orelegium, las Adnuntiationes festibitatum, otro breve texto y un calendario que comienza «Incipit martirumlegium» ${ }^{4}$. A partir de la página 35 es donde comienza el originario $\mathrm{Li}$ ber comicus, y termina bruscamente en la pág. 496.

1. Antes de todo comentario e interpretación, presentaremos las nuevas glosas en su contexto, que no aparece en la publicación de Vivancos, con unas breves notas y aclaraciones, respetando la numeración del autor citado y aportando el texto de la Vulgata, de donde están tomados estos pasajes ${ }^{5}$.

p. 230

53. cum illut bibam in $i(. . . ? .$.$) lo beua.$

Obviamente es la Glosa del pasaje de Mateo XXVI, 29, referente a la última cena de Jesús con sus apóstoles, que dice in diem illum, cum illud bibam vobiscum. Es claro que la glosa está incompleta, y que el glosador transcribiría una amplia glosa desde el in.... Lo que nos importa es lo legible, lo beba, con la forma definitiva del pronombre átono complementario, y el verbo con la correspondiente inseguridad fónica y gráfica ${ }^{6}$.

54. traderet traidor.

Esta glosa aparece en el Glosario de Silos, pero con diferente significado. Corresponde al pasaje de Mateo XXVI, 45, et Filius hominis tradetur in manus peccatorum; pero bien podría interpretar el de Juan XIII, 11, Sciebat enim quisnam esset qui traderet eum.

Mas como esta primera parte de la Pasión coincide con el citado de Mateo, nos inclinamos por él ${ }^{7}$ como base del texto glosado.

\footnotetext{
${ }^{3}$ Este Liber comicus ya había sido editado por G. Morin en 1893, con el título de Liber Comicus sive lectionarius Missae quo Toleta Ecclesia ante annos mille et ducentos utebatur, Maredsous, 1893.

${ }^{4}$ Cf. M. Vivancos, (loc. cit.), págs. 255 y ss. Véase allí la descripción detallada del ms.

${ }^{5}$ Citamos por La Santa Biblia. Vulgata latina y su traducción por el Ilmo. Dr. D. Félix Torres Amat, Barcelona, Imprenta Barcelonesa (6 vols.), 1885. Pensemos que estos pasajes de las Horas canónicas eran tomados en parte de los Evangelios, de los Salmos, de las diversas Cartas, de Lecturas de los Santos Padres, etc.

${ }^{6}$ Recordemos, a tal efecto, el viejo y conocido adagio latino medieval Beati hispani quibus uiuere est bibere, que muestra la indistinción de la labiodental y la bilabial.

7 También en Mateo 24 aparece la forma tradetur (per quem Filius hominis tradetur), pero corresponde a diferente pasaje.
} 
Conviene precisar que es más un comentario que una glosa, puesto que no traduce la forma verbal, sino que añade el sustantivo del mismo étimo, posiblemente para hacer comprender al lector de dónde procede la palabra traidor, porque este término es y era mucho más fuerte semánticamente y pragmáticamente que el verbo tradere; o quizás para explicar a unos estudiantes cómo se formaba una familia de palabras romances sobre el mismo étimo. El glosista quiso enfatizar que quien entregó a Jesús fue un traidor.

p. 231.

55. protestatus afirmat.

La glosa fuera del contexto no es fácilmente interpretable. Hay que acudir, sin embargo, al texto: «et protestatus est et dixit» (Juan XIII, 21), que se traduciría 'y abiertamente declaró y dijo'. El glosista traduce protestatus est por afirmat, en presente, con un afán de actualizar el pasaje, y manteniendo la clase verbal.

56. quo quien.

Corresponde al pasaje de Juan XIII, 21, haesitantes de quo diceret, cuyo término se repite más adelante (Juan 24): «quis est de quo dicit». Desde el punto de vista del romance se percibe claramente la distinción del relativo-interrogativo referido a personas, frente al de no-personas.

\section{Scariothis} traidor

Glosa la frase dedit Judae Simonis Iscariotae (Juan XIII, 26); pero de nuevo vemos que comenta y adjetiva en vez de traducir. Entre los evangelistas sólo Marcos lo llama traidor, y Lucas (VI, 16) proditor. Es decir, que el glosista le aplica, como había hecho más arriba (glosa 54), el apelativo de traidor, en una forma semiculta.

\section{p. 232.}

58. nunquam scandalizabor ........ non $s$ (ilegible).

Pretende aclarar las palabras de Pedro al Señor: «ego nunquam scandalizabor» (Mateo XXVI, 33) 'yo nunca te negaré ni abandonaré'.

59. oportuerit abinierat.

Aclara la secuencia del parlamento de Pedro «Etiamsi oportuerit me mori tecum, non te negabo» (Mt. XXVI, 35) 'aunque tenga que morir contigo...'.

Como se ve, la forma de la glosa está parcialmente romanceada, pues conserva, por error de copista seguramente, la $-t$ final de tercera persona. 
Abiniera, equivalente al posterior conviniera, es de avenir 'ocurrir', ya muy general en el siglo XIII (Ver Primera Crónica General y Crónica de Veinte Reyes $)^{8}$. Por vez primera aparece aquí con significado de 'ocurriera y conviniera', en un pluscuamperfecto de valor irreal.

60. sustinete state.

Es un sinónimo del verbo que aparece en el pasaje Sustinete hic et vigilate mecum (Mateo XXVI, 38) 'aguardad en vela aquí junto a mí'. Sustinere con esta acepción era más inusual que state; por contra, éste tenía mayor fuerza y expresividad semántica 'manteneos en pie, firmes'.

61. progressus despartiorr.

Sospechamos que la lectura que hace de las dos letras finales de esta palabra no es correcta; creemos que la forma escrita es despartioss 'avanzó, caminó'.

Se glosa con ello la frase de Mateo XXVI, 39 «et progressus pusillum...», 'y avanzando unos pasos....'. Como se ve, traduce en forma personal un participio latino.

62. factus ahorços.

63. prolixius longa.

Estas dos glosas comentan conjuntamente un pasaje de Lucas XXII, 43, «et factus in agonia, prolixius orabat» ' $\mathrm{y}$ angustiado agónicamente, rezaba con más intensidad'; pasaje que aparece en la Vulgata, pero que otras versiones bíblicas suprimen (versículos 42 y 43 ).

factus in agonia [ahorços] 'se esforzó hasta el extremo', 'se angustió en grado sumo'. El evangelista Marcos, como médico, no encontró otra metáfora más expresiva para el sufrimiento y pánico de Jesús ante la inminencia de la muerte que el de la agonía.

Ahorços: se aforçó 'se esforzó'. Vemos la pérdida de la $f$ - en un verbo compuesto de preposición.

prolixius [longa] 'por más tiempo', 'más largamente'. Se suprime el grado comparativo del adverbial original.

Esta glosa aparece en el Glosario de Silos.

${ }^{8}$ Cf. R. Menéndez Pidal, Primera Crónica General, Madrid, 1977 (que reproduce la de 1906). Para la Crónica de Veinte Reyes véase nuestra edición (la primera que se ha publicado), Ayuntamiento de Burgos, 1991, con estudios histórico, literario, paleográfico y lingüístico a cargo de Gonzalo Martínez Díez, José Fradejas Lebrero, José Manuel Ruiz Asencio y César Hernández Alonso. 
64. pre de.

prae tristitia (Lc. XXII, 45) 'a causa de la tristeza', 'de tristeza'.

p. 233.

65. promtus ahorzado

He aquí una polisemia de ahorzado, de ahorzarse, que traduce más arriba a factus in agonia y aquí a promtus 'dispuesto', 'animado'. Aparece en el contexto Spiritus quidem promtus est (Mt. XXVI, 41).

66. signum sennal.

Glosa que coincide, aunque con distinto significado, con una del Glosario silense.

El término signum aparece en Mt. XXVI, 48 y en Marcos XIV, 44. Aquí se glosa el primer texto.

67. ut ergo in qual.

En esta glosa vemos una referencia anafórica que no tiene el original.

p. 234.

68. ut impleretur ke complierrat.

ut impleretur sermo quem dixit (Juan XVIII, 9), 'para que se cumpliera lo que había dicho'.

Complire aparece en el Glosario de Silos con una equivalencia distinta. Dice: impleverat : efectus complendi.

Destaca la imprecisión ortográfica en las glosas.

p. 235

69. reus culpado.

Aparece en la oración reus est mortis (Mt. XXVI, 66).

En el Glosario latino-español de Toledo de fines del siglo XIV, según puede verse en A. Castro ${ }^{9}$, rreus: culpado.

70. colafis punnos.

Et colaphis eum ceciderunt (Mt. XXVI, 67), 'le dieron puñetazos'.

Punnos: 'puñadas'. Así aparece en el Glosario tardío que acabamos de mencionar.

\footnotetext{
${ }^{9}$ Américo Castro, Glosarios latino-españoles de la Edad Media, Madrid, 1936.
} 
Como se ve, se trata de un buen número de glosas romances para unos breves pasajes, el de la última cena, la oración del huerto y el prendimiento de Jesús. Conviene advertir que en este espacio no aparecen glosas latinas que sí aparecen antes y después en número de 52 .

Las glosas son del mismo copista del manuscrito y están en letra muy pequeña. Vivancos supone que fueron escritas en el primer cuarto del siglo XII.

Todas ellas, excepto tres, son glosas de palabras; las otras tres lo son de cláusulas oracionales. Mayoritariamente traducen el término original, la mitad verbos o deverbativos; pero, como vimos, algunas suponen un comentario, una toma de postura. $\mathrm{Al}$ ir interlineadas van superpuestas sin ningún tipo de conector (del tipo id est...).

2. Al llegar aquí tenemos que preguntarnos de nuevo: ¿con qué finalidad, por qué y para qué se escribieron? Y seguidamente ¿por qué se glosaba y por qué se mezclaba el latín con el romance, si bien de manera desproporcionada?

¿Y por qué en esta época y no antes? ¿Por qué no están glosados, por ejemplo, los Beatos?

Responder a todas estas preguntas y a otras que se plantean ante la lectura directa de las glosas nos llevaría un espacio del que aquí no disponemos. Remitimos a los interesados en las glosas a nuestra edición (por primera vez facsímil de las Emilianenses, AH. 60, y las Silenses, BL. 30853; transcripción cuidadosa, comentario y estudio de todas las notas latinas y romances; con sólidos estudios paleográfico, histórico literario y lingüístico), que ofrece una nueva interpretación de las glosas ${ }^{10}$.

Mas aunque no podamos extendernos cuanto desearíamos en estas cuestiones, sí nos referiremos a ellas de la manera más sintética posible.

Comenzaremos manifestando que no se debe buscar una razón común, un objetivo fijo y único a la actividad glosística de estos textos de carácter religioso. Apenas nada tienen que ver las notas, comentarios y addendas del Emilianense 60 con el de Silos (BL. 30853) o con estas notas que presentamos aquí. Ya explicamos detenidamente ${ }^{11}$ que aquél presenta un texto abundantísimamente anotado con varios miles de indicaciones de carácter sintáctico y morfosintáctico, y con glosas latinas y romances de diversa índole (sinónimos, comentarios, paráfrasis, etc.), como guía del maestro de latín para explicar el texto a unos novicios que se estaban formando.

Son la primera muestra espléndida de un método de enseñar latín en latín, la primera muestra de una tradición latino-romance, y el más antiguo testimonio de las primeras frases escritas en romance en España.

${ }^{10}$ Las Glosas Emilianenses y Silenses (op. cit.).

${ }^{11}$ Las Glosas Emilianenses y Silenses (cit.), págs. 63 y ss. 
Las Silenses de BL 30853, al igual que las del BL $39851^{12}$ y éstas que comentamos aquí, son totalmente distintas. Responden a una larguísima actividad glosística de tipo léxico, generalmente, que pretende aclarar los textos de muy diferentes maneras.

Son auténticas glosas al estilo europeo.

Queda descartada toda hipótesis de que sirvieran de apoyo a la predicación. Ya lo demostramos en su día y recientemente lo ha ratificado Díaz y Díaz ${ }^{13}$.

Casi ningún texto de los glosados es apto para la predicación; ningún predicador se apoyaría en segmentación gramatical de oraciones y cláusulas, de sujetos y predicados para hacerlo; ni sería tan ridículamente retorcido como para hacer anotaciones en latín, otras pocas en romance y dos en vascuence (en las Emilianenses), para predicar en romance al pueblo. Por otra parte, la predicación no era ni es actividad prioritaria de los benedictinos de Silos ni de San Millán, salvo la que destinaban a la Comunidad. Sólo hay que leer con atención la Regla de San Benito ${ }^{14}$-a la que más adelante nos referiremos- y conocer mínimamente la vida de estos religiosos para descartar tal hipótesis. Y ¿cómo pensar que el Penitencial del Silense BL. 30853 podía ser objeto de predicación? ¿Se iba a predicar a los fieles ni aun a todos los religiosos, novicios y postulantes - muchos de ellos niños- los más graves pecados de las gentes de la época y la penitencia que correspondía a cada uno?

De una vez por todas, hay que desechar tan frívola hipótesis. Quien tenga la menor experiencia de predicación y conozca las glosas de cerca, sonreirá ante tal interpretación.

Distintos son los casos del manuscrito silense BL 30851 y del Liber comicus (BNP. N.a.l. 2171), que comentamos aquí.

En aquél, como bien ha estudiado Díaz y Díaz se glosan los himnos litúrgicos del oficio divino utilizado por monjes o clérigos seculares, pero desconocido para el pueblo seglar de aquellos tiempos y de los actuales. Tampoco parecen materias temáticamente adecuadas a la predicación. Sí podría serlo este breve Pasaje de la Pasión que glosa el monje en el Liber co-

\footnotetext{
12 Véase el artículo de Manuel Díaz y Díaz («Las glosas protohispánicas», en Actas del III Congreso Internacional de Historia de la Lengua Española, Madrid, Arco-Libros, 1996, págs. 653-666), que, aparecido tras la redacción de este trabajo nuestro, revisa la distinción entre «Manuscritos glosados» y «manuscritos con glosas», la procedencia de algunos manuscritos de Silos, algunas cuestiones filológicas de ciertas glosas y la finalidad de las glosas. Por razón de tiempo el autor no pudo tener en consideración más que en nota final los estudios y análisis de Las Glosas Emilianenses y Silenses, aquí citado, y sus aportaciones.

${ }_{13}$ M. Díaz y Díaz, «Las glosas protohispánicas», (loc. cit.).

14 Cito por Regula sanctissimi Patris nostri Benedicti abbatis... novissima, castigataque editio, Matriti, MDCCIC (apud Blasium Roman).
} 
micus, si bien no parece habitual extraer un brevísimo pasaje de la Feria $V$ in cena Domini del Breviario para predicar, cuando en los Evangelios (Mateo, Juan, Marcos y Lucas) - de donde están tomados los textos- están desarrollados. Y, sobre todo, cuando el glosista tiene presentes estos pasajes evangélicos para sus anotaciones, como se deduce de las referencias que hemos visto.

Tampoco nos parece convincente la hipótesis de Bezler ${ }^{15}$, aceptada recientemente por Díaz y Díaz, de que el Penitencial glosado en el Silense 30853, y sólo ese, estuviera anotado como ayuda a clérigos seculares, confesores inexpertos y poco cultos como guía de confesión. Poco les podría ayudar en la confesión la aclaración de palabras por otras latinas - de semejante dificultad - y unos cientos de términos en romance.

Partiremos de que las Glosas pretenden aclarar y explicar pasajes de determinados textos religiosos; así como del hecho de que es en los Monasterios (pequeños primitivos o grandes monasterios) donde se anotan dichos textos, por regla general.

Las anotaciones y glosas sólo pudieron ser hechas por unos monjes cultos, conscientes del valor de su tarea y de que su trabajo rendía un servicio a la Comunidad.

Una hipótesis que explique la finalidad de las glosas - como dijimos, descartamos las Emilianenses, que tienen un fin y objetivo propios- es que los monjes glosadores lo hicieron con afán didáctico para que cualquier otro monje que leyera aquellos pasajes los comprendiera mejor.

Otra es que, refiriéndonos al Penitencial silense, el monje anotara el texto para comentarlo y explicarlo en clases de moral, de catequética penitencial, del viejo derecho canónico. En este caso estaríamos en una finalidad didáctica semejante a la de las notas del Emilianense 60.

En todo caso las dos hipótesis son compatibles perfectamente. Mas ¿qué decir de las anotaciones al Silense 30851 y a este Liber comicus que nos ocupa?

Para interpretarlo adecuadamente, nos parece indispensable atender a algunos capítulos de la Regla de San Benito, que regía la vida de estos monasterios. En el caput XLVIII se lee claramente

«Ab hora autem quarta usque ad horam quasi sextam lectioni vacent»... $\mathrm{Y}$ después de sexta, «... si alguno quisiere leer, lea de modo que no inquiete a otro...». «Desde el primero de octubre hasta principio de Cuaresma se ocuparán los monjes en leer hasta el fin de la segunda hora... Después de comer se ocuparán en leer o estudiar Salmos». Y un poco más adelante, «Al principio de Cuaresma se dará a cada monje un libro de la Biblio-

${ }^{15} \mathrm{~F}$. Bezler, Les pénitentiels espagnols, Münster, Ischendorff, 1994; especialmente págs. 313 y ss. 
teca el qual han de leer por orden y enteramente». Y seguidamente se habla de que si alguno fuese «tan flojo» que «no quiera o no pueda meditar o leer» que se ocupe en alguna obra de manos para no estar ocioso.

Es decir, que los monjes leían abundantemente libros religiosos, de Salmos, etc. ${ }^{16}$. Y puesto que esto habían de hacerlo desde su ingreso en la Comunidad, muchos de ellos - preferentemente novicios y postulantesnecesitarían aclaraciones, explicaciones y lecciones para comprender bien los textos.

Y los monjes más preparados anotaban palabras, términos y frases que les parecían difíciles, o desusadas en el latín eclesiástico habitual en el Monasterio, para hacer más comprensibles los pasajes que más les interesaban. $\mathrm{Y}$, además de una finalidad didáctica que podemos llamar «abierta» o general para la Comunidad, podemos conjeturar muy verosímilmente que las anotaciones eran guías y aclaraciones que el propio monje glosista utilizaría bien en meditaciones dirigidas a la Comunidad, bien en clases. Es decir, que anotaba los textos para servicio propio y para el de los demás monjes.

Aun creo muy posible que el Abad del Monasterio encomendara a uno o a varios monjes esta tarea «ilustradora», para facilitar la lectura de ciertos libros por parte del resto de la Comunidad ${ }^{17}$.

Tampoco puede descartarse que algún monje, concentrado en la lecturameditación de determinados pasajes quisiera aclarar el contenido, y aun reinterpretar levemente una palabra con otras que le venían a la mente por asociación, para otra posible lectura.

En todo caso, el objetivo de todas estas glosas es aclarador, explicitador e ilustrativo, bien con proyección didáctica y abierta hacia todos los posibles lectores de la Comunidad, bien con intención personal, didáctica y evocadora.

Son, pues, diversas las razones de la actividad glosadora, aun cuando tengan todas en común el afán didáctico.

La razón de que una mayoría se haga en latín y unas pocas en romance nos parece clara: por un lado, toda actividad intelectual de la época se hacía en latín; y cuando el monje no encontraba la palabra latina justa, plasmaba la romance más esclarecedora. En las latinas se ve algo sintomático, de modo general, la glosa es más sencilla y frecuente en el latín hablado eclesiástico que el término glosado y muchas de ellas próximas a las

\footnotetext{
${ }^{16}$ En efecto, los novicios se ejercitaban, aún hoy se ejercitan en el estudio de los himnos litúrgicos, y para ello comenzaban por traducirlos para comprenderlos perfectamente.

${ }^{17}$ De ningún modo creemos que estas anotaciones se hicieran, como pretende M. C. Vivancos, pensando en los numerosos peregrinos que acudían al Monasterio a lo largo del siglo XII a venerar el sepulcro de Santo Domingo. Difícil es que tuvieran acceso a los monasterios, y raro que la mayoría de ellos supiera leer latín. Por otra parte, ¿qué explicación se daría a las glosas realizadas en épocas anteriores, incluso un siglo antes?
} 
formas romances derivadas o equivalentes (agonia, uigor, iunctura, regia, miliario, etc.).

Suele decirse que no se funden glosas latinas y romances, y ésa es la norma; pero no faltan casos que desdicen tal aserto. Ejemplos: agonia: agonia, alacriter uel uigor del Liber comicus; defuerit: menos si fuerat (30853); quilibet abscisus est: monaco taillatu abieret a so membra; etc.

Cuestión íntimamente relacionada con lo aquí expuesto es si los glosistas utilizaron o no algún Glosario previo.

Ya en su día ${ }^{18}$ nos pronunciamos negativamente sobre este particular en lo referente a las conocidas por Glosas Emilianenses y Silenses. En el caso que nos ocupa aquí la ratificación es aún más nítida. Son muy pocos los términos aparecidos en estas Glosas que aparecen con tales significados o equivalentes en alguno de los Glosarios ${ }^{19}$, y algunos de ellos en construcciones distintas de las aquí ofrecidas. Pero aun cuando fueran muchas más las coincidentes, no creo que podamos aceptar, salvo en algún caso aislado, que el glosista utilizara un Glosario.

Aceptar que un monje culto, maestro de novicios - ya de latín o de Teología - necesitara acudir a un glosario latino-latino o latino-romance supone un menosprecio absoluto de los saberes de aquellos monjes, que con no escasa cultura, podían leer el resto de los textos directamente en latín.

Por otra parte, quienes han leído las glosas y las han analizado paso a paso - no por referencias-, si poseen unos conocimientos no muy profundos de latín, comprenderán que no hay que ser Nebrija para poder aplicar los sinónimos, parónimos y explicaciones que hay en las glosas. No es un latín esotérico, sino llano y bastante asequible, el de los textos glosados.

Y desde otro punto de vista ¿cómo explicar que sólo necesitasen Glosarios para un número escaso de pasajes glosados? ¿Para los demás no lo necesitaban o no iban a leerlos los otros monjes? Inadmisible, ya que, a veces, los pasajes glosados no son cerrados ni completos, sino partes de un pasaje mucho más amplio, como es el caso que nos ocupa.

El que existieran Glosarios no implica que los glosistas los utilizaran ${ }^{20}$. La confección de aquellos era a posteriori, y como tarea académico-científica de carácter colectáneo sobre textos; pero eso no implica que los utilizaran como Diccionario de sinónimos o de traducción. Entre otras razones, porque muchas glosas son aclaraciones, referencias indirectas, comentarios, evocaciones, etc., y no traducción literal de términos, ni alternancia de sinónimos.

\footnotetext{
${ }^{18}$ Loc. cit., págs. 71 y ss.

${ }^{19}$ Cf. Miguel Vivancos (loc. cit.), págs. 69 y ss., y 259.

${ }^{20}$ Para nuestra hipótesis de por qué se glosa en romance y precisamente en esta época, véase nuestra edición (cit).
} 